\title{
A REVISED VERSION OF THE ANISN CODE
}

BY

WILLIAM G, PRICE, JR,

\section{PLASMA PHYSICS LABORATORY}

\section{MASTER}

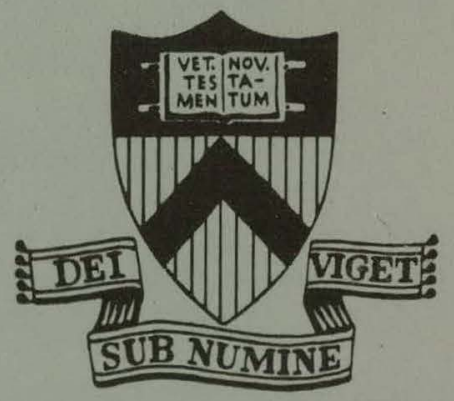

\section{PRINCETON \\ UNIVERSITY PRINCETON, NEW JERSEY}

This work was supported by U. S. Atomic Energy Commission Contract AT (11-1) -3073. Reproduction, translation, publication, use, and disposal, in whole of in part, by or for the United States Covernment is permitted. 


\section{DISCLAIMER}

This report was prepared as an account of work sponsored by an agency of the United States Government. Neither the United States Government nor any agency Thereof, nor any of their employees, makes any warranty, express or implied, or assumes any legal liability or responsibility for the accuracy, completeness, or usefulness of any information, apparatus, product, or process disclosed, or represents that its use would not infringe privately owned rights. Reference herein to any specific commercial product, process, or service by trade name, trademark, manufacturer, or otherwise does not necessarily constitute or imply its endorsement, recommendation, or favoring by the United States Government or any agency thereof. The views and opinions of authors expressed herein do not necessarily state or reflect those of the United States Government or any agency thereof. 


\section{DISCLAIMER}

Portions of this document may be illegible in electronic image products. Images are produced from the best available original document. 


\title{
A Revised Version of the ANISN Code
}

\author{
William G. Price, Jr. \\ Plasma Physics Laboratory, Princeton University \\ Princeton, New Jersey 08540
}

\begin{abstract}
PPL-ANISN is a revised version of the ANISN discrete ordinates transport theory code. It features several improved input options and a provision for binary output of its principal results.
\end{abstract}

This report was prepared as an account of work This report was prepared as an account of work sponsored by the United United States Atomic Energy the United States nor the United States Atomic Energy Cominission, nor any of their employees, nor any of their contractors, subcontractors, or their employees, makes any warranty, express or implied, or assumes any legal liability or responsibility for the accuracy, completeness or usefulness of any information, apparatus,
product or process disclosed, or represents that its use would not infringe privately owned rights. 
INTRODUCTION

PPL-ANISN is a revised version of the one-dimensional discrete ordinates transport theory code ANISN. ${ }^{1}$ The changes were programed at the Plasma Physics Laboratory to add a number of useful input options and to meet a requirement for binary output of the principal results (for use in other programs). It is based upon the IBM/360 version ${ }^{2}$ of ANISN distributed by the Radiation Shielding Information Center in April, 1972.

This report summarizes the ANISN input specification and describes the revised options. It also provides information on the execution of PPI-ANISN.

\section{INPUT REQUIREMENTS}

The input for PPL-ANISN is changed very little from that for the version on which it is based. An input card stream may contain one or more stacked cases, with a separator card between each. The bulk of the data is read by the AREAD subroutine, ${ }^{3}$ an improved version of the original FIDO input routine.. AREAD accepts a much greater variety of option codes and can, for example, retrieve common data from files other than the main input stream. 
The section below summarizes the PPL-ANISN card input requirements. This is a slight revision of section III of the ANISN manual, with changes incorporated to describe the PPL version. All cards except the title are to be in AREAD format. Title card - format (12A4, 12X, I12)

1. Title - 48 characters maximum

2. 0 or maximum execution time in hundredths of seconds 15 \$ Integer parameters [36]

1. ID problem ID number

2. ITH 0 - forward solution

1 - adjoint solution

3. ISCT maximum order of scatter found in any zone

4. ISN order of angular quadrature

5. IGE 1 - slab; 2 - cylinder; 3 - sphere

6. IBL left boundary condition

0 - vacuum (no reflection)

1 - reflection

2 - periodic

3 - white/albedo

7. IBR right boundary condition

same options as IBL

8. IZM number of zones or regions

9. IM number of mesh intervals 
10. IEVT eigenvalue type

$$
\begin{aligned}
& 0 \text { - fixed source } \\
& 1 \text { - k calculation } \\
& 2 \text { - a calculation } \\
& 3 \text { - concentration search } \\
& 4 \text { - zone width search } \\
& 5 \text { - outer radius search } \\
& 6 \text { - buckling search }
\end{aligned}
$$

11. IGM number of energy groups

12. IHT position of o total in cross section table

13. IHS position of $\sigma_{g g}$ (self-scatter) in cross section table

14. IHM length of cross section table

15. MS cross section mixing table length (10\$, 11\$, 12*)

16. MCR number of cross section sets to be read from cards $\left(14^{*}\right)$

17. MTP number of cross section sets to be read from tape $(13 \$)$

18. MT total number of cross section sets (elements + mixtures)

19. IDFM 0 - density factors $\left(21^{*}\right)$ not used

$$
\text { 1. - density factors used }
$$

20. IPVT 0 - no effect

$$
\begin{aligned}
& 1 \text { - enter } k_{0} \text { as PV }\left(16^{*}\right) \\
& 2 \text { - enter } \alpha_{0} \text { as PV }
\end{aligned}
$$

21. IQM 0 - no effect

$$
1 \text { - enter distributed source }(17 *)\{I P M=0\}
$$


22. IPM 0 - no effect

1 - enter shell source $\left(18^{*}\right)$

by group and angle $\{I Q M=0\}$

IM - enter shell source by interval, group, and angle $\left\{I_{Q M}=0\right\}$

23. IPP interval number which contains shell source if IPM $=1 ; 0$ otherwise

24. IIM inner iteration maximum

25. IDI 0 - no effect

add 1 to print angular flux

add 2 to punch scalar flux

add 4 to write the XTROUT information

add 8 to suppress printing of the source and scalar flux

26. ID2 0 - no effect

1 - use "TAPEMAKER"-prepared group independent cross section tape (containing MTP materials)

2 - use cross sections and fixed source from previous problem

3 - use internal TAPEMAKER option

27. ID3 0 - no effect

$\mathrm{N}$ - compute $\mathrm{N}$ activities by zone where $\mathrm{N}$ is any positive integer

28. ID4 0 - no effect

1 - compute $\mathrm{N}$ activities by interval (where $\mathrm{N}$ refers to ID 3 ) and print them

-1 print and also punch activities by interval 
29. ICM outer iteration maximum

use $\mathrm{ICM}=1$ if $\mathrm{IEVT}=0$

ICM may be 0 if IFN $<0$ and IPRT $=4$ or 5

30. IDATI 0 - all data in core

1 - cross sections and fixed sources stored on tape

2 - fluxes and currents on tape also

31. IDAT2 0 - no effect

$>0$ - execute diffusion solution for specified groups (24\$) as long as outer iteration \# IDAT2

32. IFG 0 - no effect

1 - flux weight cross sections (27\$ and 28\$)

33. IFLU 0 - step model used when linear extrapolation yields negative flux (mixed mode)

1 - use linear model only

2 - use step model only

3 - weighted difference model (preferred option)

4 - linear model, weighted model if negative

34. IFN 0 - enter fission guess $(2 *)$

1 - enter flux guess $\left(3^{*}\right)$

2 - use fluxes from previous case

$<0$ - restart by reading XTROUT data from unit \#|IFN $\mid$

35. IPRT 0 or 2 or 4 - print cross sections

1 or 3 or 5 - do not print cross sections

0 or 1 - print all balance tables

2 or 3 - print only summary balance table

4 or 5 - do not print any balance table 
36. IXTR 0 - calculate $P_{L}$ scattering constants (Legendre coefficients)

1. - read $P_{L}$ constants from cards $(34 *)$

16* Floating point parameters [14]

1. EV first guess for eigenvalue

2. EVM eigenvalue modifier

3. EPS epsilon - accuracy desired

4. BF buckling factor, normally 1.420892

5. DY cylinder or plane height for buckling correction

6. D2 plane depth for buckling correction

7. DFMI transverse dimension for void streaming correction

8. XNP normalization factor

9. PV $0.0, k_{0}$, or $\alpha_{0}$ according to IPVT $=0,1$, or 2

10. RYF $\lambda_{2}$ relaxation factor, normally 0.5

11. XLAL, point flux convergence criterion if entered greater than zero

12. XLAH upper limit for $\left|1.0-\lambda_{1}\right|$ used in linear search

13. EQL elgenvalue change epsilon

14. XNPM new parameter modifier NOTE: The above data is followed by a $T$.

cross" sections $\{$ ID $2=0\}$

13\$ Library ID numbers [MTP] \{MTP > 0 \}

14* Card cross sections [IHM $\times$ IGM $\times$ MCR] $\{M C R>0\}$ NOTE: If entered, the above data is followed by a T. 
Cross Sections \{ID2 $=3\}$

13\$. Library ID numbers [MTP] $\{$ MTP $>0\}$ NOTE: If entered, the above data is followed by a $T$.

14 * Card cross sections [IHM $\times$ IGM], MCR sets [MCR > 0\} NOTE: Each card cross section set is entered as an individual $14^{*}$ arraý, followed by $\mathrm{a} \cdot \mathrm{T}$.

Fixed Source $\{$ IEVT $=0$ and $\operatorname{ID} 2 \neq 2\}$

17* Distributed source $[I M \times I G M],\{I Q M=1\}$ (source per unit volume)

18* Shell source [MM $\times$ IPM $\times$ IGM] $\{$ IPM $>0\}$ (flux on outside of interval)

NOTE: If entered, the above data is followed by a $T$.

Flux or Fission Guess $\{$ IFN $=0$ or 1$\}$

2* Fission density [IM] [IFN $=0$ \}

$3 *$ Flux guess [IM $\times$ IGM] $\{$ IFN $=1\}$

NOTE: If entered, the above data is followed by a $T$.

Remainder of Data

1* Fission spectrum [IGM]

4* Radii by interval boundàry [IM +1 ]

5* Velocities [IGM] (must truly be velocity if IEVT $=2$ )

6* Angular quadrature weights [MM ]*

7* Angular quadrature cosines [MM] 
$8 \$$ zone numbers by interval [IM]

9 \$ Material numbers by zone [IZM]

10\$ Mixture numbers in mixing table [MS] $\{$ MS $>0$ \}

II\$ Component numbers in mixing table [MS] \{MS >0\}

12* Number densities in mixing table [MS] [MS >0\}

$19 \$$ order of scatter by zone. [IZM] \{ISCT > 0 \}

20* Radius modifiers by zone [IZM] [IEVT $=4$ \}

21* Density factors by interval [IM] \{IDFM $=1$ \}

$22 \$$ Material numbers for activities [ID3] $\{$ ID3 $>0\}$

23\$ Position numbers for activities [ID3] [ID3 >0\}

$24 \$$ Diffusion calculation or infinite medium markers [IGM] \{IDAT2 $>0$ \}

25*. Albedo by group - right boundary [IGM] $\{$ IBR $=3$ \}

26* Albedo by group - left boundary [IGM] [IBL $=3$ \}

27\$ Few group parameters [5] \{IFG $=1$ \}

1. ICON 0 - no effect

$$
\begin{aligned}
& \pm 1 \text { - micro cross sections desired } \\
& \pm 2 \text { - macro cross sections desired } \\
& \text { (minus implies cell weighting) }
\end{aligned}
$$

2. IHTF position of $\sigma_{\text {total }}$ in weighted cross sections

3. IHSF position of $\sigma_{g \rightarrow g}$ in weighted cross sections (minus implies upscatter removal)

4. IHMF table length of weighted cross sections

5. IPUN 0 -print without punching

1 - punch and print weighted cross sections -1 - punch without printing 
$28 \$$ Few group number for each multigroup [IGM] $\{$ IFG $=1\}$

$29 \$$ summation limits for activities [ $2 \times$ ID3] \{ID3 > 0$\}$

34 * $P_{L}$ scatter constants [JT $\times$ MM] $\{$ IXTR $=1\}$

JT = ISCT for plane or sphere

$J T=(I S C T \times(I S C T+4)) / 4$ for cylinder, truncated to

the next lower integer for cylinders when ISCT is odd:

38 * densities for use in

activity calculation [IM $x$ ID 3 ] $\{$ ID $3>0\}$

NOTE: The above data is followed by a T.

After completing each case, PPL-ANISN determines whether or not to proceed with another (e.g., an adjoint) by trying to read another card. If it detects an end-of-file, or if there is a card with exactly "END " in columns 1-4, then it stops; otherwise it looks for another full case with its own title card, etc. 
REVISED OPTIONS

Several new options are available with the PPL version of ANISN; these are discussed below. Refer to the ANISN User's Guide for descriptions of the regular ANISN options.

ID1 - The appropriate value for ID1 is obtained by adding together the values representing each of several possible options: (a) add 1 to print the angular flux; (b) add 2 to punch the scalar flux; (c) add 4 to write the output from this case on the XTROUT file (described in detail in the Programmer's Guide); and (d) add 8 to suppress the printing of the source and the scalar flux. Option (c) was added to allow auxiliary programs to obtain the ANISN results, option (d) was added to save paper. IPRT - The expanded choice of values for IPRT is provided to reduce the expense of balance table computation in many-zone systems and to allow the ICM $=0$ option.

IFN - When IFN $=-\mathrm{N}$, a flux guess is read from an XTROUT-format file with logical unit number $N$. This allows one, for example, to restart a previous case or to use an old flux result as a starting guess.

ICM - It is now meaningful to set $I C M=0$. No flux calculation will be performed, so the activities and group collapsing will be performed using the flux guess, e.g., the flux in the XTROUT file if IFN $<0$. If IFN $\geq 0$ then IPRT must be 4 or 5 since the angular flux guess required for balance table computation will not exist. ID2 - The TAPEMAKER program, which prepares a special space-saving cross section input "tape" for ANISN, has been dismembered and reconstituted as an integral part of the PPL version of ANISN. 
When ID.2 $=3$ ANISN will try, after reading the $15 \$$ and $16^{*}$ arrays and their "T", to read $13 \$$ array (with MTP entries) terminated with a "T" and then/or set (MCR decks) of 14* arrays, each one. terminated with a "T".

Cross section mixing is done in the regular ANISN manner as specified by the $10 \$, 11 \$$, and 12* arrays entered later. The special "tape" is not made available for later use, but the size of memory required is greatly reduced when this option is used. ID 3 - When activities are to be computed (ID3 >0) two new arrays are required to control the energy and spatial summations. The $29 \$$ array - J (2, ID 3$)$ - should be entered as a series of pairs of numbers, one pair for each activity. The first number of the Kth pair, $J(I, K)$, is set to 1 if it is $<I$ or > IGM, while the second number, $J(2, K)$, is set to IGM if it is $<1$ or $>$ IGM (thus 0,0 is equivalent to 1 , IGM). The summation over energy for each activity will be controlled by the corresponding entries in the 29\$ array: only the groups from $\mathrm{J}(\mathrm{l}, \mathrm{K})$ through $J(2, K)$ will be added. As an example of its use, the $29 \$$ array can be set to extract neutron-only integrals in neutron/gamma coupled problems. 
The 38* array - D(IM,ID3) - is used to supply optional material density profiles for each activity. If $M(K)$, the niaterial number provided in the $22 \$$ array for the Kth activity, is positive, then the real density profile of material $M(K)$ in each interval is used as the density for the activity calculation; however, if $M(K)$ is negative, then the entries $D(I, K)$ are used (except that if $D(I, K)=0$ for $I=1$ to $I M$ then $D(I, K)$ is reset to 1.0). A new column in the activity table print-out contains "Real," "1.0," or "38*" to indicate which option was used. 


\section{XTROUT FILE}

The PPL-ANISN XTROUT option, triggered by adding in 4 when computing IDI, dumps out most of the input and the computed results. This information can be used later by other programs, for example to calculate extra activities from the fluxes or to calculate perturbation integrals. Since the data is written in binary form the process is quick and the storage requirement is minimal. Successive dumps from stacked cases follow each other in the XTROUT file. The following parameters not defined in the ANISN input are needed to describe the output format:

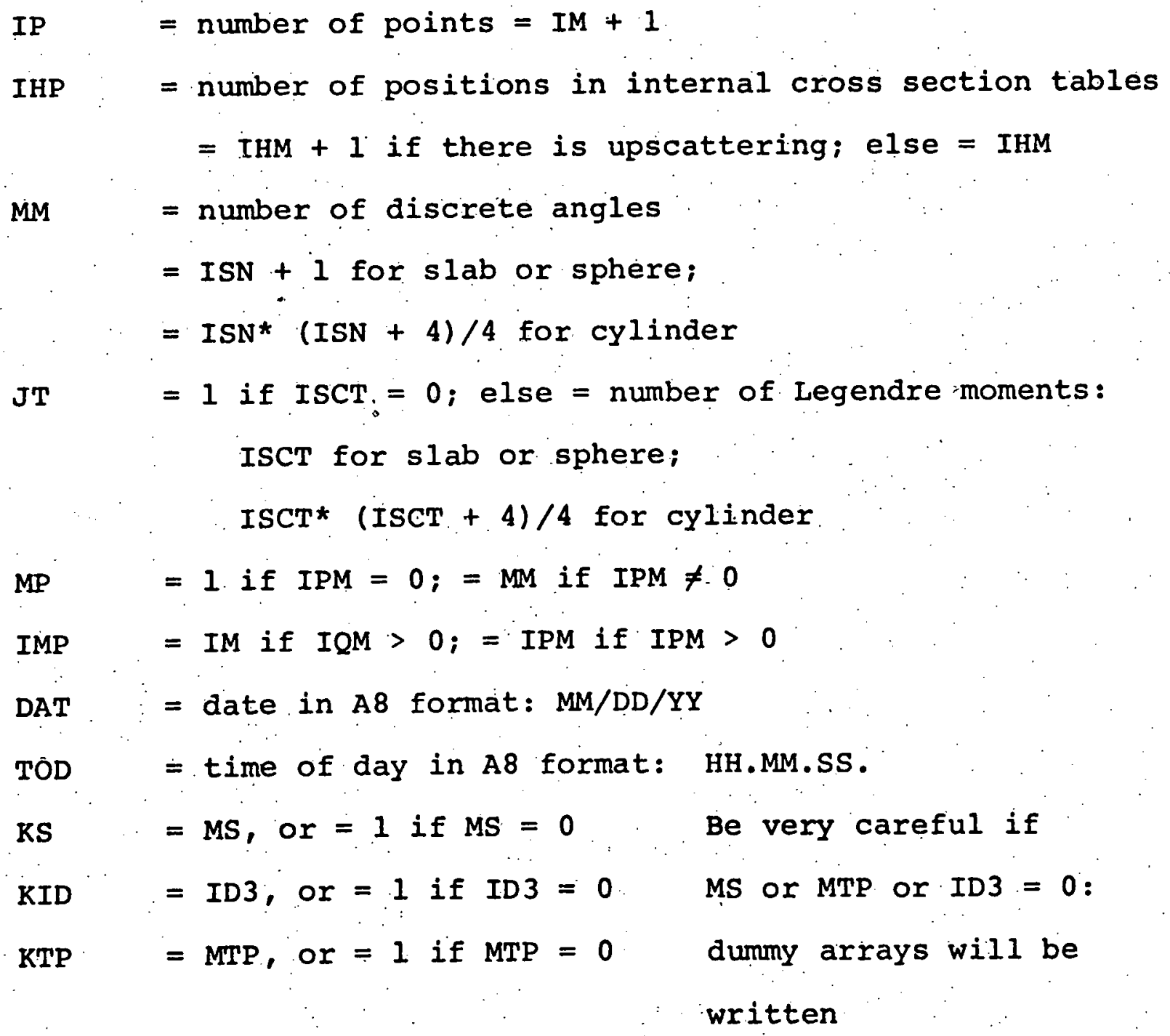


The following FORTRAN-like statements deșcribe the output:

\begin{tabular}{|c|c|c|c|c|}
\hline 1. & WRITE (3) & T,DAT, TOD & & $T(12)$ is the problem title \\
\hline 2. & $"$ & $\operatorname{KFIX}(36)$ & $15 \$$ & integer constants \\
\hline 3. & $"$ & FLT (14) & $16 *$ & real constants \\
\hline 4. & $"$ & $\mathrm{XKI}(\mathrm{IGM})$ & $1 *$ & fission spectrum \\
\hline 5. & $"$ & FD (IM) & 2* & fission density guess \\
\hline 6. & $"$ & $R(I P)$ & 4 * & radii \\
\hline 7. & $"$ & $\operatorname{VE}($ IGM) & $5 *$ & velocities \\
\hline 8. &. & $\mathrm{~W}(\mathrm{MM})$ & $6^{*}$ & quadrature weights \\
\hline 9 . & $"$ & DSN (MM) & $7 *$ & quadrature cosines \\
\hline 10. & $"$ & MA (IM) & $8 \$$ & zone numbers \\
\hline 11. & $"$ & $M Z(I Z M)$ & $9 \$$ & material numbers \\
\hline 12 . & $"$ & $\mathrm{MB}(\mathrm{KS})$ & $10 \$$ & mixing numbers \\
\hline 13. & $"$ & $\mathrm{MC}(\mathrm{KS})$ & $11 \$$ & component numbers \\
\hline 14 . & $"$ & $\mathrm{XMD}(\mathrm{KS})$ & $12 \$$ & component densities \\
\hline 15. & $"$ & MTT (KTP) & $13 \$$ & ID'S of materials on tape \\
\hline 16. & $"$ & J $5(\mathrm{IZM})$ & $19 \$$ & order of scatter \\
\hline 17. & $"$ & $\mathrm{RM}(I Z M)$ & $20 *$ & radius modifiers \\
\hline 18. & $"$ & $\mathrm{DF}(\mathrm{IM})$ & $21 *$ & density factors \\
\hline 19. & $"$ & J3 (KID) & $22 \$$ & materials for activities \\
\hline 20. & $"$ & J4 (KID) & $23 \$$ & positions for activities \\
\hline 21 & $"$ & IGT (IGM) & $24 \$$ & diffusion markers \\
\hline 22 & $"$ & ART (IGM) & $25 *$ & right albedo \\
\hline 23 & $"$ & ALFT (IGM) & $26 *$ & left albedo \\
\hline 24. & $"$ & IFGP (5) & $27 \$$ & few group parameters \\
\hline
\end{tabular}




\begin{tabular}{|c|c|c|c|c|}
\hline 25 & WRITE (3) & IFGG (IGM) & $28 \$$ & few group numbers \\
\hline 6. & $"$ & $\mathrm{~J} 6(2, \mathrm{KID})$ & $29 \$$ & activity group limits \\
\hline 7. & $"$ & $V(I M)$ & $30 *$ & interval volumes \\
\hline 3 & $"$ & $A A(I P)$ & $31 *$ & boundary areas \\
\hline . & $"$ & WD (MM) & $32 *$ & weight*cosine \\
\hline 0 . & " & $M R(M M)$ & $33 \$$ & index of reflection an \\
\hline $3 i$. & $"$ & $\operatorname{PNC}(\mathrm{MM}, \mathrm{JT})$ & $34 *$ & Legendre coefficients \\
\hline 2 . & $"$ & $C F(I M, K I D)$ & $38 *$ & activity densities \\
\hline
\end{tabular}

DO $1 \mathrm{~J}=1$; IGM

WRITE (3) (XN $(I, J), I=1, I M) \quad$ scalar flux

WRITE (3) $(B(M, J), M=1, M M)$ boundary flux

WRITE (3) ((XND $(I, M, J), I=I, I P)$,

$$
M=1, M M) \quad \text { angular flux }
$$

IF (ISCT.EQ:0) GO TO 1

WRITE (3) ( $(X J(I, I, J), I=1, I M)$ ，

$$
\mathrm{L}=1, \mathrm{JT})
$$

Legendre components

1 CONTINUE

DO $2 \cdot J=1$, IGM

WRITE(1 or 2)

\& $((\mathrm{CRX}(I, J, K), I=I, I H P), K=1, M T)$ cross sections

IF ( (IQM*IM + IPM*MM). EQ.O) GO TO 2

WRITE (1 or 2)

\& $((Q(M, I, J), M=1, M P), I=1, I M P)$ source

\section{CONTINUE}

RETURN 
The binary cross section library XSECLIB is assumed to be in the standard ANISN format. Each "material" is written into the library with the following two "unformatted" write statements:

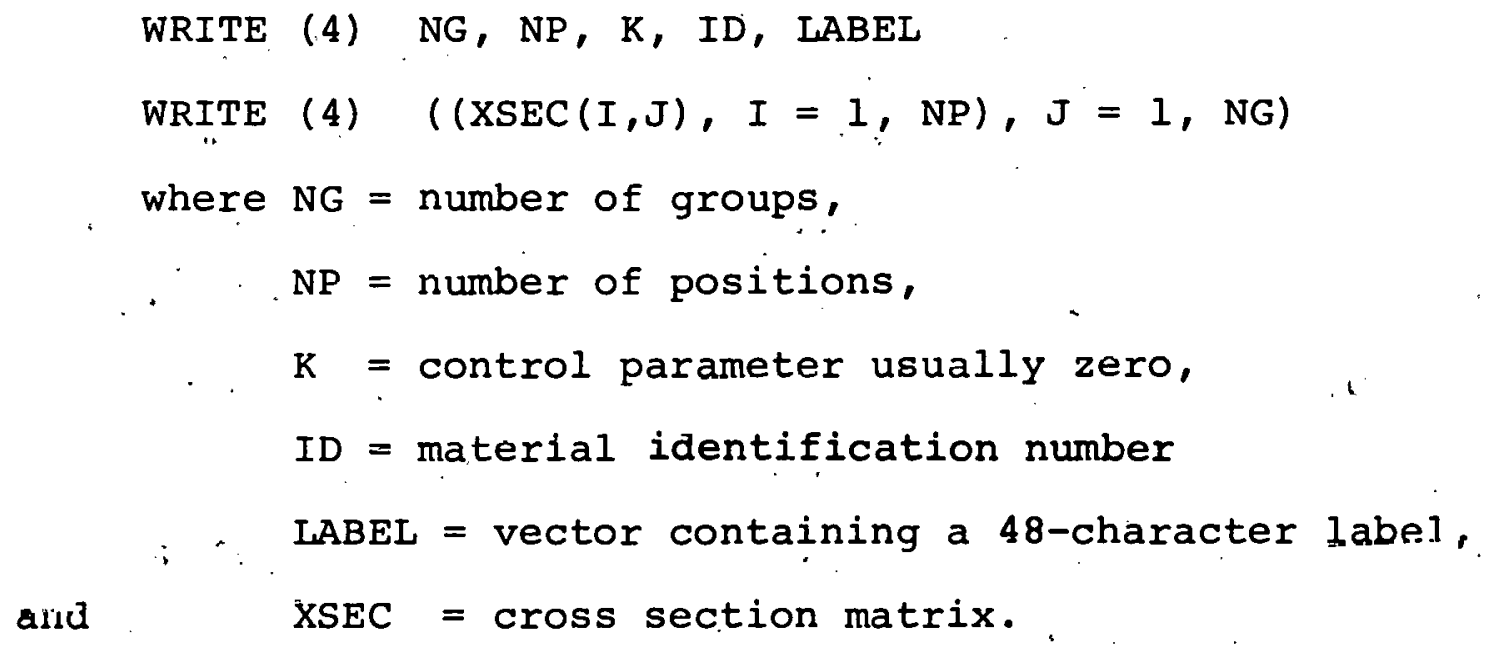

The library is terminated by a header record with $\mathrm{K}=7$. PPL-ANISN will look through the entire library for each material requested, rewinding once if necessary.

When a Tapemaker "tape" is supplied instead of a standard binary library, it is assumed to contain all the cross sections for MTP materials, organized by group rather than by material. The output from Tapemaker is a binary library described by the following FORTRAN statements:

$$
\text { DO } 2 J=1 \text {, NG }
$$

2 KRITE (4) $(X S E C(I, L, J), I=I, N P), L=1, M T P)$ 
PROGRAM SIZE

PPL-ANISN has been written in IBM/360 Fortran-IV and compiled with the H-level compiler. This requires about 80 seconds and $240 \mathrm{~K}$ bytes on the $360 / 91$. To reduce the memory requirement at execution the following overlay scheme is recommended--a root segment containing the main program, CONTRL, SKPBUF, BULKBU, and the service routines; and three overlays sharing the same space: PLSNT, TP, ADJNT, TAPE, WOT8, S804, S805, S814, and S966; or GUTS, DT, CELL, S807, S810, S821, S824, S833; and S851; or FINPR, FINPRI, PUNSH, XTROUT, BT, SUMARY, FACTOR, FEWG, AND WATE. The memory size required to execute PPL-ANISN with this overlay structure on the IBM/360 has been approximately (in bytes) $102,000+4 \times$ words in /BULKBU/plus I/O Buffers. The size of /BULKBU/ is set by the declarations in the main program ANISN. It is up to the user to run only those cases which fit his compiled version.

The number of words required in /BULKBU/ by a given set of data will be approximately the larger of:

$$
\begin{aligned}
& \text { (a) }(M C R+M T P) * I H M *\left\{\begin{array}{c}
I G M \text { if ID2 }=0 \\
\text { else } 1
\end{array}\right\} \\
& \text { or (b) }[I M *(J T+I)+M M] *\left\{\begin{array}{c}
\text { IGM if IDAT1 } \neq 2 \\
\text { else } 1
\end{array}\right\} \\
& +[I H M * M T+I P Q M] *\left\{\begin{array}{c}
\text { IGM if IDATI }=0 \\
\text { else } 1
\end{array}\right\} \\
& +[I S C T+3 * \text { JT }+ \text { ID } 3+6 * \text { MM }+14] * \text { IM } \\
& \text { where IPQM }=\left\{\begin{array}{l}
I P M * \text { MM If IPM } \neq 0 \\
\text { Or IM if IQM } \neq 0
\end{array}\right\} \text { and the other symbols are }
\end{aligned}
$$
defined in the ANISN input section. 
INPUT/OUTPUT UNITS

At least 9 I/O unit numbers are used by PPL-ANISN. Additional units may be specified to satisfy input redirection requests ( $X$ or $\mathrm{Y}$ options) to the AREAD card scanner. IBM/360 JCL examples of the basic units are given below.

Unit 5: This is the input unit from which the basic data cards are read. It is assumed to supply 80-column card images.

//FT05F001 DD *

Unit 6: This is the printed output unit, and is assumed to be a line printer accepting a carriage control character and 132 printing columns.

$/ /$ FT06F001 DD SYSOUT $=\mathrm{A}$

Unit 7: This is the punched output unit, and is assumed to punch 80-column cards.

$/ / F T 07 F 001 \quad D D \quad$ SYSOUT $=B$

Unit 4: This is the cross section library XSECLIB. It must be produced by an auxiliary program, and should have a structure appropriate to FORTRAN "unformatted" reads and writes.

$/ / F T 04 F 001, ' D D \quad D I S P=($ SHR, KEEP $)$, DSN = XSECLIB,

$\mathrm{UNIT}=2314$, VOL $=\mathrm{SER}=\mathrm{PPL} 789$,

$D C B=(R E C F M=V B S, L R E C L=7290$,

BLKSIZE $=$ 7294) 
Unit 3: This is the XTROUT file which receives the new output of ANISN as a series of FORTRAN "unformatted" writes. $/ /$ FT03F001 DD DISP $=($ NEW, PASS $)$, DSN $=$ XTROUT,

$$
\begin{aligned}
& \text { UNIT }=2314, \text { VOL }:=\text { SER }=\text { PPL78, } \\
& \text { DCB }=(\text { RECFM }=\text { VBS, LRECL }=7290 \\
& \text { BLKSIZE }=7294)
\end{aligned}
$$

Units $1,2,8, \& 9$ : These are scratch units required by ANISN. They are written and read "unformatted."

$/ /$ FT01F001 DD UNIT $=$ SYSDA, SPACE $=($ TRK, $(100 ; 100))$, $D C B=($ RECFM $=$ VBS, $L R E C L=7290$, BLKSIZE $=7294)$. 
PROGRAMMER'S GÜIḌE .

As noted earlier, PPL-ANISN is based on the April 1972 IBM/360 version of ANISN distributed by RSIC. All the changes made to that program have been incorporated into an input deck for a simple editing program; the deck is thus a concise and precise compilation of the changes.

The deck consists of edit control cards and new FORTRAN cards. The control cards (which have a period in column one) contain one of the following five codes and either one sequence number or a range of sequence numbers:
-A M
copy through card $M$, then insert any new FORTRAN cards up to the next control card.
.B $\mathrm{M}$ copy through card $M-1$, then insert any new FORTRAN cards.
. C M N
copy through card $M-1$, delete cards $M$ through $N$, then insert any new FORTRAN cards. if $\mathrm{N}$ is blank, set $\mathrm{N}=\mathrm{M}$. .
.D. $M$ N copy through card $M-1$, then delete cards $M$ through $N$.
. END if $\mathrm{N}$ is blank, set $\mathrm{N}=\mathrm{M}$. copy the rest of the cards.

The deck of changes can perhaps be used to incorporate the PPL-ANISN improvements into newer releases of ANISN or versions already adapted to other machines. 
Only a few local system subroutines have been used, and they can easily be replaced. The main program calls CANSTA, which inhibits the ordinary (at PPL) suppression of SYSABEND dumps after catastrophic failure. The internal timing routine ITIME calls the REAL function CUTIME, whose value is the elapsed CPU time in seconds (it is initialized on its first call).

Since ANISN will sometimes perform "illegal" computations, SETERR is called first to suppress, and later to enable, underflows, overflows, and divide checks. CHKERR returns the number of times each of these events occurred.

Note that a version date is compiled into PPL-ANISN and printed in the output. This can be invaluable in deciaing later just what has been run (as long as it is kept up to date).

\section{ACKNOWLEDGMENT}

This work was supported by U. S. Atomic Energy Commission Contract AT(11-1)-3073; use was made of computer facilities supported in part by National Science Foundation Grant NSF-GP579; support was also received from the Electric Power Research Institute Project RP 113. 
REFERENCES

[1] W. W. Engle; Jr., "A User's Manual for ANISN, A OneDimensional Discrete ordinates Transport Code with Anisotropic Scattering," Oak Ridge Fasseous Diffusion Plant Report K-1693 (1967). This report is included in Ref. [2].

[2] Radiation Shielding Information Center, "ANISN, a OneDimensional Discrete Ordinates Transport Code," Computer Code Collection CCC-82, Oak Ridge National Laboratory (1972).

[3] W. G. Price, Jr., "AREAD, An Input Data Processing Code," Princeton Plasma Physics Laboratory MATT-1034 (1974). 


\section{LEGAL NOTICE}

This report was prepared as an account of Government sponsored work. Neither the United States, nor the Commission, nor any person acting on behalf of the Commission:

A. Makes any warranty or representation, express or implied, with respect to the accuracy, completeness, or usefulness of the information contained in this report, or that the use of any information, apparatus, method, or process disclosed in this report may not infringe privately owned rights; or

B. Assumes any liabilities with respect to the use of, or for damages resulting from the use of any information, apparatus, method, or process disclosed in this report.

As used in the above, "person acting on behalf of the commission" includes any employee or contractor of the Commission to the extent that such employee or contractor prepares, handles or distributes, or provides access to, any information pursuant to his employment or contract with the Commission. 